\title{
Márton Veress: Karst environments-karren formation in high mountains
}

\author{
2010, Springer Science + Business Media BV, Heidelberg, Germany. ISBN: 978-90-481- \\ 3549-3, hardback, $106.95 €, 220 \mathrm{pp}, 172$ illustrations
}

\author{
Natascha Wahlberg Macías
}

Published online: 6 July 2010

(C) Springer-Verlag 2010

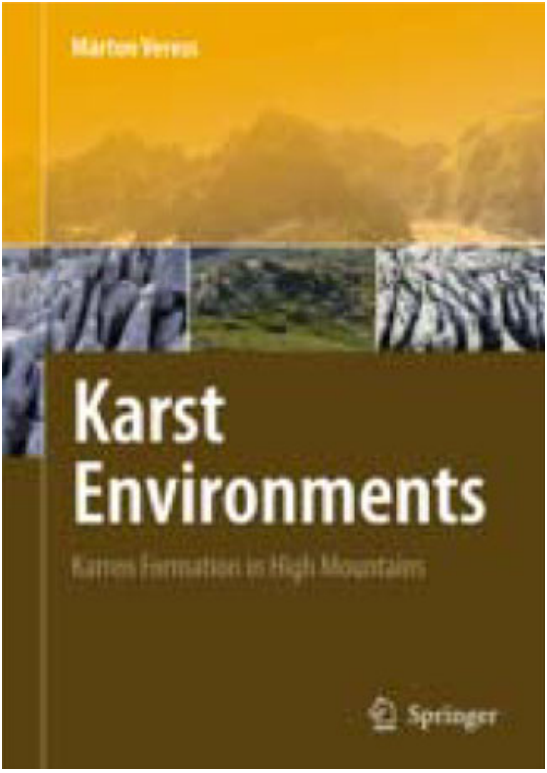

This book is based in part on the author's monograph entitled “A Magashegységi Karrosodás” (2007), published in Hungarian by the University of West Hungary.

The volume is a summary of observations during 15 years of field trips to the European Alps and results and interpretation of the data collected. The focus is on karren formations in the high mountains.
The book is organized into seven chapters. A summary of the history of research on high mountain karren is given. Characteristics of this type of environment and the development of specialized terminology for describing these areas is reviewed. Different measurement methods used for researching these areas and how to judge the age of high karren formations and their rate of their development are discussed.

Special attention is given to the diversity of forms. Karren formations are discussed as a function of the environment, climate, morphology, and development they have undergone. Formation of karren assemblages in the various zones, such as glacial valleys, mountain slopes and the higher elevations, are explained. Explanations are clear and well-written. The numerous illustrations and colored plates add greater understanding of the topics discussed.

This book is an excellent guide for professionals, researchers, graduate students and university professors. It will serve as a future reference for studies in this type of karst. It also provides very detailed information and many research method examples which are easy to follow.

N. W. Macías $(\bowtie)$

University of Malaga, Malaga, Spain

e-mail: nwmacias@hotmail.com 